\title{
Mapping the Intellectual Structure of Supply Chain Management
}

\author{
Fu-Jin $\mathrm{Hu}$ and Jen-Hwa Kuo
}

\begin{abstract}
To explore the intellectual structure of supply chain management research in the last twelve years, this study identified the most important publications and the most influential scholars as well as the correlations among these scholar's publications. In this study, bibliometric, social network, and Tag Cloud Analysis techniques are used to investigate the intellectual pillars of the supply chain management literature. By analyzing 38,806 citations of 999 articles published in SSCI journal in supply chain management area between 2001 and 2012, this study maps a knowledge network of supply chain management studies. The results of the mapping can help identify the research direction of supply chain management research and provide a valuable tool for researchers to access the literature in this area.
\end{abstract}

Index Terms-Supply chain management, bibliometric, tag cloud analysis, diffusion innovation.

\section{INTRODUCTION}

The knowledge system of each discipline is a part of a more general knowledge system as well. It plays a basic role in storage and knowledge spread in various disciplines, journals, articles, books and monographs [1]. In the formal exchange of the three ways (journals, articles, books and monographs), journal articles produce the most useful information because of their timeline as well as the evaluation of the scholars.

This study uses Bibliometrics and Social Network Analysis to understand the evolution to introduced supply chain management research from 2001 to 2012. This study, in a more objective way, uses Invisible Network of Knowledge (INK) to research the application of the smart structures of Supply chain management field.

This study defines INK as a set of interrelated invisible node. Each node provides a specific purpose for Supply chain management research and any other fields of research. With the quotation and co-citation analysis, this mode can explore the smart structures existing in any field, define its knowledge network, and further depict the process of its knowledge diffusion.

Therefore, referring to a certain discipline in the magazine articles provides an objective measurement to its development. It also provides the relative measurement on the special contribution made by the authors, books, journals and the article progress. The past twelve years has especially

Manuscript received Janaury 10, 2013; revised March 15, 2013.

Fu-Jin $\mathrm{Hu}$ is with the Graduate School of Business and Operations Management, Chang Jung Christian University in Taiwan. (e-mail: fu727@ms45.hinet.net)

Jen-Hwa Kuo is with the Graduate School of Business and Operations Management, Chang Jung Christian University in Taiwan. (e-mail:Dynaopto@gmail.com) seen extensive research on supply chain management. Yet even though supply chain management has established itself as an academic discipline, its establishment has been a slow process because researchers in this area prefer to publish their best work in more established journals. Another major obstacle to the development of supply chain management lies in the subject's unusually high degree of interaction with other disciplines.

This overlapping blurs the boundaries of supply chain management and as a result its distinct theoretical model and analytical tools are unjustly attributed to other competing fields. With limited resources contributing to the development of supply chain management, the cross-fertilization of ideas between scholars of supply chain management will be much more difficult to obtain. Consequently, while there is no doubt that there is an area or field of supply chain management, the question remains somehow unclear on what it is, how good its work is, and what are its prospects and needs for future development.

The aim of this study is to provide supply chain management researchers with a unique map to better understand supply chain management related publications and to provide a systematic and objective mapping of different themes and concepts in the development of supply chain management field. This study also attempts to help identify the linkage among different publications and confirm their status and positions in their contribution to the development of supply chain management field. The principal methods used are citation and Tag Cloud Analysis.

\section{RESEARCH PURPOSE}

The purpose of this study is to propose an Invisible Network of Knowledge theory and to explore the evolution development of Supply chain management knowledge structure during the two twelve yearss from 2001-2012. This study is to identify the most important publications and researchers, published in SCI and SSCI journals about Supply chain management issues mainly in the years of 2001-2012, as well as to establish the correlation between these publications, and correspond to different research sub-topics in the field, analyze the links between each other, and learn about its developing relationship between the knowledge structure. This study is more trying to help researchers identify the link between the publications of different researchers, as well as to confirm its position and contribution in Supply chain management development.

Therefore, this study is trying to reach the following research purposes by applying Invisible Network of Knowledge (INK):

1) To establish the most important and the most influential 
scholars, journals, books and articles in Supply chain management study with an objective analysis of the citation.

2) To provide important insights and impact on current and future research paradigms with the analysis of Invisible network of knowledge in Supply chain management research, as well as the relative research of scholars and practitioners in the management level.

\section{StUdies OF ACADEMIC LITERATURE}

There are a number of techniques that can be used to study a body of literature. Most frequent is the simple literature review where a highly subjective approach is used to structure the earlier work. Objective and quantitative techniques have recently become popular with more databases available online for use. These techniques adopt author citations, co-citations, and systematic review [2] to examine the invisible knowledge network in the communication process by means of written and published works of a given field. These techniques are attractive because they are objective and unobtrusive [3].

Several studies have used the bibliometric techniques to study the literature of management research. For example, Cheng-Hua Wang, Yender McLee, and Jen-Hwa Kuo[4] explored the intellectual structure of supply chain management in its early stage of development, using principle component analysis on an author co-citation frequency matrix; Etemad [5] identified the most influential authors and studies in electronic commerce field by using citation analysis; Ponzi [6] explored the intellectual structure and interdisciplinary breadth of supply chain management in its early stage of development, using principle component analysis on an author co-citation frequency matrix; Chan, Seow and Tam [7] used citations from accounting dissertations completed during 1999-2003 to provide a ranking of accounting journals; Acedo and Casillas [8] explored the research paradigms of international management research by applying factorial analysis techniques in an author co-citation study; Ramos-Rodriguez and Ruiz-Navarro [9] examined the intellectual structure change of strategic management research by conducting a bibliometric study of the Strategic Management Journal. To the best of our knowledge, no similar study has been conducted on the current research of supply chain management. Therefore this study aims to fill a gap in supply chain management literature by applying citation and Tag Cloud Analysis to a representative sample of recent research on supply chain management collected by the Science Citation Index and Social Sciences Citation Index.

\section{Methodology}

\section{A. Research Method}

In order to understand Supply chain management's in the past, now and the future, this study investigates the relationship of the mutual the wisdom structure during the twelve years of 2001-2012. The research methods used in this study covers Bibliometric techniques and Tag Cloud Analysis.

\section{B. Research process}

First, selecting from SSCI and SCI database to collect required information about supply chain management research journals, books, and articles. Second, using Excel analysis technique to reorganize, summarize, classify, rank and filter systematically, and divide the timeline into two periods, 2001-2006 and 2007-2012, to explore the evolution of the intellectual structure in Supply chain management field.

\section{Bibliometric}

Citation analysis method is mainly used to analyze the reference phenomenon or objects of journals, papers, authors, and to explore the relationship between the sources of literature and citation. It can help researchers understand the current state of development of certain disciplines, the literature usage characteristics in the disciplines, correlation within the literatures between disciplines and the future trends of research through citation analysis.

\section{Tag Cloud}

In addition to the advantage of visual creativity and easy-to-use, Tag cloud can be used to assess cluster focus, and is beneficial to the content promotion. It is a good navigation tool to the traditional text based information retrieval system. Tag cloud can also support browsing or unexpected discovery, and can be used as a visual summary of the database content.

In this study, the Science Citation Index (SCI) and Social Sciences Citation Index (SSCI) were used for analysis. The SCI and SSCI are widely used databases, which include citations published in over 3500 world's leading scholarly journals. While there are arguments that other online databases might also be used for such analysis, using SCI and SSCI provided the most comprehensive and the most accepted databases of supply chain management publications.

Unlike other prior studies, the data used in this study were not drawn from journals chosen by peer researchers [10]. Instead, the entire databases of SCI and SSCI from 2001 to 2012 served as the universe for analysis. In order to collect the data, we used "key word" method which utilizes the SCI and SSCI databases key word search in article's title and abstract. Using "Supply chain management" as key word, this study collected 3,463 journal articles which further cited 152,181 publications as references. The cited references in these papers included both books and journal articles.

\section{RESUlts}

\section{A. Citation Analysis}

To identify the key publications and scholars that have laid down the ground work of supply chain management research, citation data were tabulated for each of the 999 source documents and 38,806 references using the Excel package. The citation analysis produced interesting background statistics, as shown in the following tables. As shown in Table I, the highly cited supply chain management journals between 2001 and 2006 was Management Science, European Journal of Operational Research, and Harvard Business Review are the top three most cited journals. 
TABLE I: THE MOST FREQUENTLY CITED JOURNALS: 2001-2006

\begin{tabular}{lc}
\hline \multicolumn{1}{c}{ Journal } & Total Citation \\
Management Science & 426 \\
European Journal of Operational Research & 229 \\
Harvard Business Review & 215 \\
International Journal of Production Economics & 200 \\
International Journal of Production Management & 182 \\
Supply Chain Management & 170 \\
Journal of Operations Management & 166 \\
International Journal of Physics Distribution & 152 \\
Journal of Business Logistics & 151 \\
Operations Research & 122 \\
\hline \hline
\end{tabular}

Table II lists the most cited journals in supply chain management area in the six years, among which Journal of Operations Management, International Journal of Production Economics, and Supply Chain Management are the top three most cited journals. The general pattern of the most cited journals shows that operations research, production management, and supply chain management.

TABLE II: THE Most FREQUENTLY Cited JouRnALS: 2007-2012

\begin{tabular}{lc}
\hline \multicolumn{1}{c}{ Journal } & Total Citation \\
Journal of Operations Management & 965 \\
International Journal of Production Economics & 950 \\
Supply Chain Management & 733 \\
European Journal of Operational Research & 706 \\
International Journal of Production Management & 685 \\
Management Science & 623 \\
Journal of Business Logistics & 452 \\
INT J PROD RES & 451 \\
Journal of Supply Chain Management & 410 \\
Harvard Business Review & 379 \\
\hline \hline
\end{tabular}

Journal articles and books combined, the top five most cited scholar between 2001 and 2006 (the first six years) were Lee HL, Fisher ML, Beamon BM, Cachon GP and Handfield R.B (See Table III). For the second six years, the status of the most important scholars changed. The top five most cited scholars were Zhu QH, Lee HL, Gunasekaran A, Carter CR, and Vachon $S$ (See Table IV).

TABLE III: Highly CiTED AuTHORS: 2001-2006

\begin{tabular}{cccc}
\hline \hline Authors & Frequency & Authors & Frequency \\
Lee HL & 118 & Simchi-Levi D. & 29 \\
Fisher ML & 32 & Tan KC & 29 \\
Beamon BM & 31 & Christopher M. & 28 \\
Cachon GP & 31 & Chen F & 26 \\
Handfield R.B. & 29 & Dyer JH & 25 \\
\hline \hline
\end{tabular}

These scholars have the most influence in the development of supply chain management area and thus collectively define this field. Their contributions represent the focus of the main research in the field and thus give us an indication of the popularity of certain Supply chain management topics as well as their historical values.

TABLE IV: HighLy CITED AUTHORS: 2007-2012

\begin{tabular}{cccc}
\multicolumn{4}{c}{ TABLE IV: HIGHLY CITED AUTHORS: 2007-2012 } \\
\hline \hline Authors & Frequency & Authors & Frequency \\
Zhu QH & 167 & Christopher M. & 76 \\
Lee HL & 136 & Sarkis J & 76 \\
Gunasekaran A & 115 & Mentzer J. T. & 69 \\
Carter CR & 104 & Eisenhardt KM & 68 \\
Vachon S & 82 & Chen IJ & 66 \\
\hline \hline
\end{tabular}

Table III and IV represent the key research themes in a field and give us an indication of the popularity of certain Supply chain management topics. The readers can find high citations are associated to what can be termed field-defining titles and they lay down the ground work for the understanding of supply chain management as a distinct phenomenon. A comparison between Table III and IV reveals some interesting patterns from the first six years (2001-2006) to the second six years (2007-2012). First, the top four most influential authors in the last five remain the same, indicating their dominant status for the past twelve years in supply chain management studies. This is also true for the top five most influential scholars in the last six years. Second, on the one hand, the most cited publications in the first six years have relatively smaller number of citations, comparing with the publications in the second six years.

The gradual increase in the total citations supports the evolving process of supply chain management research as an academic field and the process of gaining more and more recognition in the literature. On the other hand, the most influential papers in the first six years and the second six years do not change much. This indicates the development in supply chain management is slow and a few classical works and influential authors still dominate the supply chain management research. More efforts and theoretical breakthrough are thus needed in order to further advance the development of supply chain management research.

\section{B. Co-citation Analysis}

In this stage, data mapping was conducted and an intellectual structure of current Supply chain management studies was revealed. Co-citation analysis is a bibliometric technique that information scientists use to map the intellectual structure of an academic field. It involves counting documents from a chosen field - paired or co-cited documents. Co-citation analysis compiles co-citation counts in matrix form and statistically scales them to capture a snapshot at a distinct point in time of what is actually a changing and evolving structure of knowledge [11].

Co-citations were tabulated for each source documents by using the Excel package. Many of the authors had very few co-citations that were either unlikely to have had a significant impact on the development of the field or were too new to have had time to impact on the literature. To facilitate analyses and improve the probability of its success, it was made sure that all authors in the final set had at least 20 citations in the first ten years and 20 in the second six years.

Based on the total number of citations in the selected journals, the top scholars were identified, and then a co-citation matrix was built before a pictorial map was drawn to describe the correlations among different scholars. In doing so, we were following the procedures recommended by White and Griffith [12].

Social network analysis techniques were used to graph the relationships in the co-citation matrix and identify the strongest links and the core areas of interest in supply chain management [13]. Figure 1 and Figure 2 show the core research themes in Supply chain management studies, based on sampled articles with links of greater than or equal to ten co-citations shown in the network. This is produced using UCINET software [2] and shows International Journal of 
Social Science and Humanity, graphically the core areas of interest. Different shapes of the nodes result from performing a faction study of these authors. This method seeks to group elements in a network based on the sharing of common links to each other. The diagrams show that current research in supply chain management area is concentrating on the interactions of essential of technological diffusion, ethnic bulling, different cultural practices, diffusion innovation and technology adoption. The few scholars in Figure 1 and 2 with the most links (co-citation) are the super stars in digital divide research. Their heavy citations and intensive interlinks with each other undoubtedly indicate their prestigious status in supply chain management research and their publications and research work collectively define the future research directions of supply chain management studies.

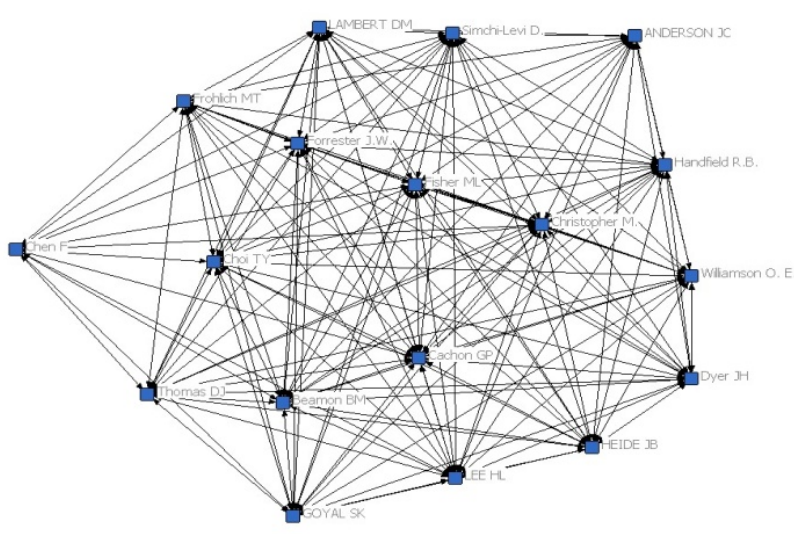

Fig. 1. Key Research Themes in SCM (2001-2006)

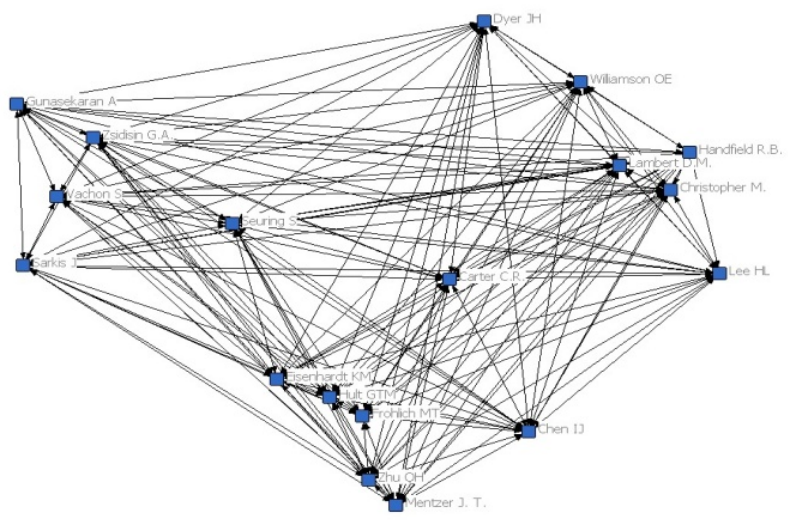

Fig. 2. Key Research Themes in SCM (2007-2012)

While the diagrams in Figure 1 and Figure 2 provide a clear picture, their foci are only on the very core areas and only a limited amount of information is revealed. By taking the co-citation matrix and grouping the authors using factor analysis of the correlations between the entries, we can determine which authors are grouped together and therefore share a common element. According to this, the closeness of author points on such maps is algorithmically related to their similarity as perceived by citers. We use r-Pearson as a measure of similarity between author pairs, because it registers the likeness in shape of their co-citation count profiles over all other authors in the set [14].

The co-citation correlation matrix was factor analyzed using varimax rotation, a commonly used procedure, which attempts to fit (or load) the maximum number of authors on the minimum number of factors. The diagonals were considered missing data and were applied the criterion of omitting the two cases [15].

Six factors were extracted from the data in the first six years (2000-2004) and together they explained over 79.6\% of the variance in the correlation matrix. Table 6 lists the six most important factors along with the authors that had a factor loading of at least 0.5 . As is usual in this type of analysis, authors with less than a 0.5 loading or with cross-loadings were dropped from the final results. We tentatively assigned names to the factors on the basis of our own interpretation of the authors with high loadings. Our interpretation of the analysis results is that supply chain management research in this period is composed of at least three different sub-fields: racial divide, urban supply chain management and digital service (Please see Figure 1). We made no attempts to interpret the remaining factors due to their small eigenvalues.

They have also been excluded from Table V. Similarly, studies on supply chain management also clustered on different research themes between 2005 and 2009 and together they explained over $79.2 \%$ of the variance in the correlation matrix of the second six years, as pictured in Figure 2. Table VI lists the eight most important factors along with the authors that had a factor loading of at least 0.5 . We also tentatively assigned names to the factors on the basis of our own interpretation of the authors with high associated loadings. Our interpretation of the analysis results is that supply chain management research at this stage is also composed of at least four key subfields: technological diffusion, ethnic bulling, different cultural practices and diffusion innovation.

Fig. 1 and Table $\mathrm{V}$ clearly indicated that the most influential authors in supply chain management studies between 2001 and 2006 clustered together. The first factor is System dynamics in Table $\mathrm{V}$ appears to define racial divide by Forrester, Fisher and Cachon.

TABLE V: AUTHOR FACTOR LOADINGS: 2000-2004

\begin{tabular}{|c|c|c|c|c|c|}
\hline $\begin{array}{l}\text { Factor: } 1 \\
\text { System } \\
\text { dynamics }\end{array}$ & $\begin{array}{c}\text { Varianc } \\
\mathrm{e} \\
49.90 \%\end{array}$ & $\begin{array}{l}\text { Factor: } 2 \\
\text { Working } \\
\text { partnerships }\end{array}$ & $\begin{array}{c}\text { Varianc } \\
\text { e } \\
27.70 \%\end{array}$ & $\begin{array}{l}\text { Factor: } 3 \\
\text { Supplier } \\
\text { networks }\end{array}$ & $\begin{array}{l}\text { Varianc } \\
\text { e } \\
9.80 \%\end{array}$ \\
\hline Forrester J.W. & 0.985 & Anderson JC & 0.906 & Dyer JH & 0.573 \\
\hline Fisher ML & 0.977 & Dyer JH & 0.812 & $\begin{array}{l}\text { Williamson } \\
\text { O.E. }\end{array}$ & 0.571 \\
\hline Cachon GP & 0.949 & Heide JB & 0.812 & Heide JB & 0.571 \\
\hline $\begin{array}{l}\text { Simchi-Levi } \\
\text { D. }\end{array}$ & 0.930 & $\begin{array}{l}\text { Williamson } \\
\text { O.E. }\end{array}$ & 0.795 & & \\
\hline Beamon BM & 0.904 & Choi TY & 0.781 & & \\
\hline $\begin{array}{l}\text { Christopher } \\
\text { M. }\end{array}$ & 0.901 & Handfield R.B. & 0.733 & & \\
\hline Goyal SK & 0.893 & Chen F & 0.579 & & \\
\hline Thomas DJ & 0.886 & & & & \\
\hline Lambert DM & 0.783 & & & & \\
\hline Frohlich MT & 0.73 & & & & \\
\hline Lee HL & 0.708 & & & & \\
\hline $\begin{array}{l}\text { Handfield } \\
\text { R.B. }\end{array}$ & 0.594 & & & & \\
\hline
\end{tabular}


The second factor working partnerships is defined by Anderson, Dyer and Heide, and appears to represent urban supply chain management research. The three factor supplier network is defined by Dyer, Williamson and Heide.

For the second six years, Fig. 2 and Table VI clearly indicated that the most influential authors in supply chain management studies between 2007 and 2012 also clustered together. The first factor in Table appears to define the supply chain management information distortion is defined Lee, Frohlich, and Hult.

\begin{tabular}{lccr}
\multicolumn{4}{c}{ TABLE VI AUTHOR FACTOR LOADINGS: 2007-20012 } \\
\hline $\begin{array}{l}\text { Factor: } 1 \\
\text { Information } \\
\text { distortion }\end{array}$ & $\begin{array}{c}\text { Factor: } 2 \\
\text { 4.30\% Reverse } \\
\text { logistics }\end{array}$ & $\begin{array}{c}\text { Factor: } 3 \\
\text { Transaction-cost } \\
\text { economics }\end{array}$ & $12.60 \%$ \\
\hline Lee HL & 0.902 Carter C.R. & 0.947 Williamson OE & 0.734 \\
Frohlich MT & 0.890 Seuring S & 0.917 Eisenhardt KM & 0.698 \\
Hult GTM & 0.884 Vachon S & 0.909 Dyer JH & 0.691 \\
Chen IJ & 0.863 Zhu QH & 0.866 Gunasekaran A & 0.54 \\
Mentzer J.T. & 0.857 Sarkis J & 0.861 & \\
$\begin{array}{l}\text { Lambert D.M. } \\
\text { Christopher }\end{array}$ & 0.821 Zsidisin & 0.755 & \\
$\begin{array}{l}\text { M.A. } \\
\text { Eisenhardt }\end{array}$ & 0.808 Handfield & 0.553 & \\
$\begin{array}{l}\text { KM } \\
\text { Gunasekaran } \\
\text { A }\end{array}$ & 0.695 & & \\
Williamson & 0.675 & & \\
OE & 0.668 & & \\
$\begin{array}{l}\text { Dyer JH } \\
\text { Handfield } \\
\text { R.B. }\end{array}$ & 0.615 & & \\
\hline
\end{tabular}

Factor 2 is defined by Carter, Seuring and Vachon, appears to reverse logistics on supply chain management. Factor 3 represents transaction-cost economics of supply chain management are defined by Williamson, Eisenhardt and Dyer.

\section{Tag Cloud Analysis}

In addition to the advantage of visual creativity and easy-to-use, Tag cloud can be used to assess cluster focus, and is beneficial to the content promotion. It is a good navigation tool to the traditional text based information retrieval system. Tag cloud can also support browsing or unexpected discovery, and can be used as a visual summary of the database content. They provide a visualization of a collection of simple texts by visually depicting the tag frequency by font size. In use, tag clouds can evolve into the associated data source over time. Tag clouds are not only used to display tag sets but are also increasingly applied in other contexts and for various data sets, for instance, in the areas of information visualization or text summarization. As in Fig. 3 and Fig. 4, they show the core research themes supply chain management studies, based on sampled article with links of key word than show in the tag clouds.

This is produced using software of Tag Crowd web and shows graphically the core areas of interest. The diagrams show that current research in web service area is concentrating on the keyword of essential of supply chain management, risk, performance, green, logistics, information and integration.

\section{chain}

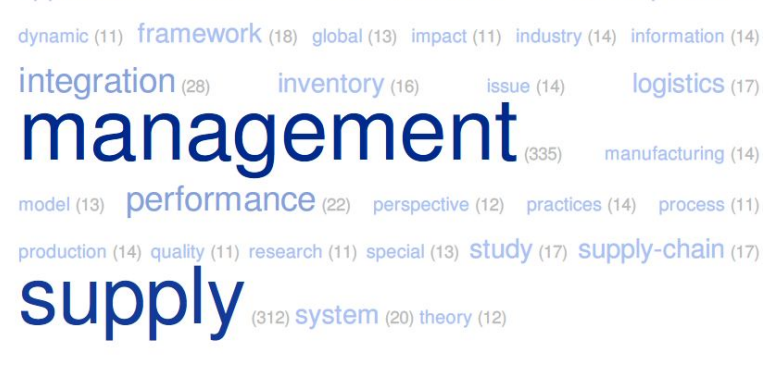

Fig. 3. Tag clouds in key word of web services (2001-2006)

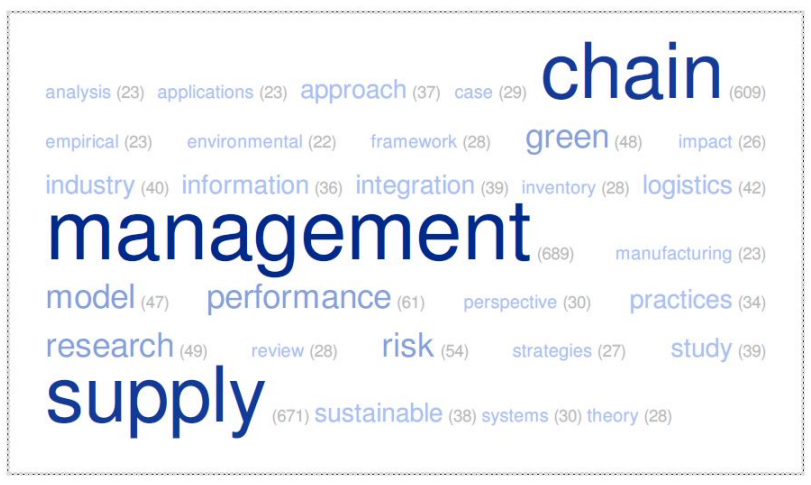

Fig. 4. Tag clouds in key word of Web Services (2007-2012)

\section{CONCLUSION}

The past twelve years years have seen extensive research on supply chain management. This study investigates supply chain management research using citation and Tag Cloud Analysis data published in SCI and SSCI between 2001 and 2012.

The mapping of the intellectual structure of supply chain management studies indicates that supply chain management has somehow created its own literature and that it has gained the reputation as a legitimate academic field, with supply chain management specific journals gaining the status required for an independent research field, such as the Journal of Operations Management and International Journal of Production Economics. Given that the supply chain management is still young and our analysis has shown that it has an evolving structure, it is believed that supply chain management publication outlets will gain more popularity and prestige that is required to become a more prominent academic field when we learn more about current paradigms and the key research themes in supply chain management studies, how they relate, and what they stand for. With more scholars and more resources contributing to the supply chain management area, a better academic environment conducive for research ideas' cross-fertilizing will be formed and supply chain management, as a field, will gain more momentum for further development.

\section{REFERENCES}

[1] P. R. Chandy, and T. G. F. Williams, "The impact of journal and authors on international business research: A citation analysis of JIBS 
articles," Journal of International Business Studies, vol. 25, no. 4, pp. 715-728, 1994

[2] B. M. Compain, "The digital: facing a crisis or creating a myth?" MIT Press, 2001.

[3] E. Garfield, Citation Indexing: Its Theory and Application in Science, Technology, and Humanities, New York: Wiley, 1979.

[4] Cheng-Hua Wang, Yender McLee, and Jen-Hwa Kuo, "Mapping the Intellectual Structure of Supply chain management," International Journal of Social Science and Humanity, vol. 1, No. 1, pp. 49-54, 2011.

[5] H. Etemad, "E-commerce: The emergence of a field and its knowledge network," International Journal of Technology Management, vol. 28, pp. 776-800, 2004.

[6] L. J. Ponzi, "The intellectual structure and interdisciplinary breadth of supply chain management: A bibliometric study of its early stage of development," Scientometrics, vol. 55, pp. 259-272, 2002.

[7] K. C. Chan, G. S. Seow, and K. Tam K., "Ranking accounting journals using dissertation citation analysis: A research note," Accounting Organizations and Society, vol. 34, pp. 875-885, 2009.

[8] F. J. Acedo, and J. C. Casillas, "Current paradigms in the international management field: An author co-citation analysis," International Business Review, vol. 14, pp. 619-639, 2005.

[9] A. R. Ramos-Rodriguez, and J. Ruiz-Navarro, "Changes in the intellectual structure of strategic management research: A bibliometric study of the strategic management journal, 1980-2000," Strategic Management Journal, vol. 25, pp. 981-1004, 2004.

[10] K. A. Walstrom, and L. Leonard, "Citation classics from the information systems literature," Information \& Management, vol. 38 , pp. 59-72, 2000.

[11] H. G. Small, "Macro-level changes in the structure of co-citation clusters: 1983-1989," Scientometrics. vol. 26, pp. 5-20, 1993.
[12] E. Garfield, Citation Indexing: Its Theory and Application in Science, Technology, and Humanities. New York: Wiley, 1979.

[13] A. Pilkington, and T. Teichert, "Management of technology: Themes, concepts and relationships," Technovation, vol. 26, pp. 288-299, 2006.

[14] S. P. Borgatti, M. G. Everett, and L. C. Freeman, UCINET for windows: Software for social network analysis, MA: Harvard, 2002.

[15] D. H. White, and K. W. McCain, "Visualizing a discipline: An author co-citation analysis of information science," Journal of the American Society for Information Science, vol. 49, pp. 327-355, 1995.

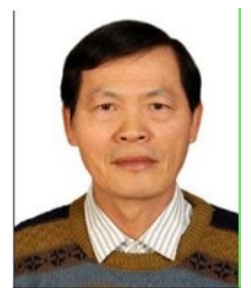

Fu-Jin $\mathbf{H u}$ is a doctoral student at the Graduate School of Business and Operations Management, Chang Jung Christian University in Taiwan. He received MS degree from the Department of Information and Communication in Southern Taiwan University of Science and Technology, Taiwan. His research interests include supply chain management and information systems management.

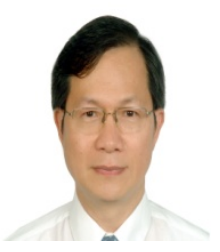

Jen-Hwa Kuo is a doctoral student at the Graduate School of Business and Operations Management, Chang Jung Christian University in Taiwan. He received MS degree from the Graduate Institute of Industrial Economics in National Central University, Taiwan. His research interests include enterprise resource planning, management information system and accounting. ( 